\title{
RIP CURRENTS ON A BARRED BEACH
}

\author{
Andrea Ruju ${ }^{1}$, Pablo Higuera ${ }^{1}$, Javier L. Lara ${ }^{1}$, Iñigo J. Losada ${ }^{1}$ and Giovanni Coco ${ }^{1}$
}

This work presents the numerical study of rip current circulation on a barred beach. The numerical simulations have been carried out with the IH-FOAM model which is based on the three dimensional Reynolds Averaged NavierStokes equations. The new boundary conditions implemented in IH-FOAM include three dimensional wave generation as well as active wave absorption at the boundary. Applying the specific wave generation boundary conditions, the model is validated to simulate rip circulation on a barred beach. Moreover, this study addresses the identification of the forcing mechanisms and the three dimensional structure of the mean flow.

Keywords: nearshore circulation; rip current; barred beach; RANS

\section{INTRODUCTION}

Rip currents are seaward oriented currents usually flowing through narrow channels that cut a longshore bar system. They are driven by short wave motion and interact with the underlying sandy bottom representing an important agent for beach forms evolution. In addition, rip currents are known to be among the most dangerous phenomena for beach users.

Due to their academic and practical importance, rip currents have received an increasing attention by the costal engineering community within the last decades (Dalrymple et al., 2011). A substantial number of field and laboratory investigations have addressed the problem of rhythmic nearshore circulation including rip currents. Moreover, a wide range of numerical studies dealing with rip circulation systems are present in the literature.

In this work we investigate rip current circulation by means of the three-dimensional numerical model IH-FOAM based on the Reynolds averaged Navier-Stokes (RANS) equations. The main objective of this work is to study the formation and subsequent evolution of 3D rip current circulation. Model experiments allow for high spatial resolution and so for the use of a quasi-continuum study of the rip circulation thus overcoming limitations related to field and laboratory studies. Moreover, the use of a 3D RANS model is motivated, amongst other different numerical approaches, because the vertical structure of the motion, nonlinearity and wave breaking are directly solved without any imposed assumptions.

\section{NUMERICAL MODEL: IH-FOAM}

\section{Description}

The numerical simulations of the present paper have been fulfilled with the model called IHFOAM, see Higuera et al. (2013a, 2013b). This solver is based on OpenFOAM, a widely used open source CFD code.

It solves the three-dimensional Reynolds Averaged Navier-Stokes (RANS) equations for two incompressible phases using a finite volume discretization and the volume of fluid (VOF) method. In VOF, each phase is described by a fraction $\alpha$ occupied by the unit volume of water in the cell $(0$ means that the cell is full of air and 1 that it is full of water, being a mixture when in between). Its principal advantages are its simplicity, allowing very complex free surface configurations to be represented easily and that it involves no mesh motion, as VOF is advected. A minor disadvantage is that it becomes less effective when surface tension effects increase. However, we are dealing with relatively long wavelengths, so that only for very specific phenomena surface tension forces are not negligible. It also supports automatically several turbulence models such as k- $\varepsilon, k-\omega$ SST or LES.

On top of that, special boundary conditions which allow a simultaneous generation and active wave absorption of waves have been coded and added to the solver, so that it is now fully prepared to simulate all kinds of coastal engineering processes.

\section{Governing Equations}

The RANS equations include continuity (1) and momentum conservation (2) equations. They are the governing mathematical expressions which describe the motion of fluid flow. The assumption of incompressible fluids has been used, which is applicable for most coastal engineering practical problems.

$$
\nabla \cdot U=0
$$

\footnotetext{
${ }^{1}$ Environmental Hydraulics Institute "IH Cantabria", Universidad de Cantabria, C/ Isabel Torres no15, Parque Científico y Tecnológico de Cantabria, 39011, Santander, Spain. E-mail rujua@unican.es
} 
$\frac{\partial \rho U}{\partial t}+\nabla \cdot(\rho U U)-\nabla \cdot\left(\mu_{\mathrm{eff}} \nabla U\right)=-\nabla p^{*}-g \cdot X \nabla \rho+\nabla U \cdot \nabla \mu_{\mathrm{eff}}+\sigma \kappa \nabla \alpha$

$\rho$ is the density, which is calculated as later presented in equation (3); $U$ is the velocity vector; $p^{*}$ is the excess in the hydrostatic pressure; $g$ is the acceleration of gravity; $X$ is the position vector. The last term on the right hand side of equation (2) is the effect of surface tension: $\sigma$ is the surface tension coefficient; $\kappa$ is the curvature of the interface and $\alpha$ is the indicator function, which has already been introduced, and will be further commented later in this section. Finally $\mu_{\text {eff }}$ is the efficient dynamic viscosity, which takes into account the molecular dynamic viscosity plus the turbulent effects: $\mu_{\text {eff }}=\mu+\rho v_{\text {turb }}$. The elements in equation (2) have a particular disposition: those placed on the left hand side of the equals sign are used in OpenFOAM to assemble the coefficient matrix, and the ones on the right side are calculated explicitly to form the independent term of the equations.

Using VOF it is straightforward to calculate any of the properties of the fluid at each cell, just by weighting them by the VOF value. For example, density of the cell is computed as follows:

$$
\rho=\alpha \rho_{\text {water }}+(1-\alpha) \rho_{\text {air }}
$$

An additional equation must also be taken into account to describe the movement of the phases. The starting point for the equation which tracks the fluid movement is a classic advection equation, but as a sharp interface must be maintained and $\alpha$ must be conservative and bounded between 0 and 1 , some restrictions apply. OpenFOAM makes use of an artificial compression term instead of using a compressing differencing scheme, as follows:

$$
\frac{\partial \alpha}{\partial t}+\nabla \cdot U \alpha+\nabla \cdot U_{c} \alpha(1-\alpha)=0
$$

in which $U_{c}$ is the compression velocity.

The boundedness of such equation is achieved by means of an especially designed solver called MULES (Multidimensional Universal Limiter for Explicit Solution). It makes use of a limiter factor on the fluxes of the discretized divergence term to ensure a final value between 0 and 1 . For further reference regarding the governing equations see Rusche (2002).

\section{Solving Procedure}

Originally the solving algorithm for RANS was PISO (Pressure Implicit with Splitting of Operators), for a detailed description of the numerical solution of the equations see Kissling et al. (2010). More recent versions of the code have improvements. The new algorithm is called PIMPLE, as it is actually a mixture between PISO and SIMPLE (Semi-Implicit Method for Pressure-Linked Equations) algorithms. Both algorithms are thoroughly explained and applied for VOF in Jasak (1996). PIMPLE main structure is inherited from the original PISO, but it allows equation under-relaxation, as in SIMPLE, to ensure the convergence of all the equations at each time step.

A detailed flow chart, figure 4.1 in Higuera et al. (2013 a), was developed in order to show the full loop for solving each time step.

\section{Boundary Conditions}

The only effort done in the wave generation and absorption field for OpenFOAM was recently presented in Jacobsen et al. (2011). Their approach is quite complete, accounting a great number of wave theories. However, they lack active wave absorption on the boundary, as they use relaxation zones. This technique has clear disadvantages as the existence of a wave damping region is known to produce an increment of the mean water level [Mendez et al. (2001)]. It also increases the computational domain by around two wave lengths [Wei and Kirby (1995)], which is quite inconvenient for already large domains and prototype applications. Another drawback is that each time step the waves are multiplied by a weighting function inside the relaxation zones, so if the time steps are very small and the simulations very long, the accuracy decreases due to machine precision errors.

To account for this lack, the boundary conditions in IH-FOAM include the three dimensional generation of regular waves as defined by Stokes I, II and V, cnoidal and stream function wave theories. Also first and second order directional irregular waves and Boussinesq solitary waves are supported. Full details are provided in Higuera et al. (2013 a). 
On top of that, active wave absorption has been implemented to work simultaneously with wave generation or independently. This feature is a key point for coastal engineering as it allows for longer simulations avoiding the increase of water level and agitation.

The 2D active absorption method is used as appears in Schäffer and Klopman (2000). It is the easiest technique to be implemented considering that it is based on linear shallow water theory (as presented in equation 5). Previous works on other numerical models Torres et al. (2010), Lara et al. (2011) have shown that it works relatively well even when used for waves outside the shallow water regime.

$U h=c \eta$

where $U$ is horizontal velocity, $h$ is the water depth, $c$ is the wave celerity and $\eta$ is the free surface elevation.

In order to cancel out the incident waves, the boundary must generate a velocity equal to the incident one but in the other direction. Therefore, $U$ can be assimilated to the correction velocity, and $\eta$ with the value of the measured free surface. Since wave height is not known in advance, wave celerity can be approximated as follows: $c=\sqrt{g h}$. The active wave absorption expression is presented in equation 6 .

$U_{c}=-\sqrt{\frac{g}{h}} \eta_{I}$

in which $U_{c}$ is the correction velocity that is applied to a vector perpendicular to the boundary and pointing into the domain; and the incident wave height $\left(\eta_{I}\right)$ is calculated by subtracting the measured elevation at the wavemaker $\left(\eta_{M}\right)$ from the target one $\left(\eta_{T}\right)$, according to the expected reflection-free wave generation: $\eta_{I}=\eta_{M}-\eta_{T}$.

\section{DESCRIPTION OF THE EXPERIMENTS}

\section{Physical Experiments}

The physical modelling is included in Dronen et al. (2002). The experiments were carried out at ISVA's laboratory, in which the wave tank is $30 \mathrm{~m}$ long and $4 \mathrm{~m}$ wide. A bathymetry consisting of a bar with a rip channel was constructed. A sketch of the geometry can be seen in Figure 1. An initial part with a horizontal bottom was considered until $\mathrm{x}=6 \mathrm{~m}$. Then the bar was placed on a plane with 1:27 slope which continued until $\mathrm{x}=12.4 \mathrm{~m}$. The bar crest was $0.13 \mathrm{~m}$ high, $4.8 \mathrm{~m}$ long and $3 \mathrm{~m}$ wide, which left a $1 \mathrm{~m}$ wide rip channel. Right before the final 1:17 beach planar beach profile (which started at $\mathrm{x}=14.3 \mathrm{~m}$ ), a $1.9 \mathrm{~m}$ horizontal section was left to act as the bar trough.

Several types of waves were generated, regular waves ranging from 6 to $20 \mathrm{~cm}$ in height and from 1 to $2 \mathrm{~s}$ in period. Irregular waves ranged 6 to $18 \mathrm{~cm}$ in Hrms and 1 to $2 \mathrm{~s}$ of peak period. Water depth varied from 5 to $15 \mathrm{~cm}$ in the highest point of the bar crest. In all of the experiments the wave generator was run for at least 50 waves prior to data acquisition in order to measure only once the steady state has developed. Free surface elevation, velocity and particle tracking were recorded. 


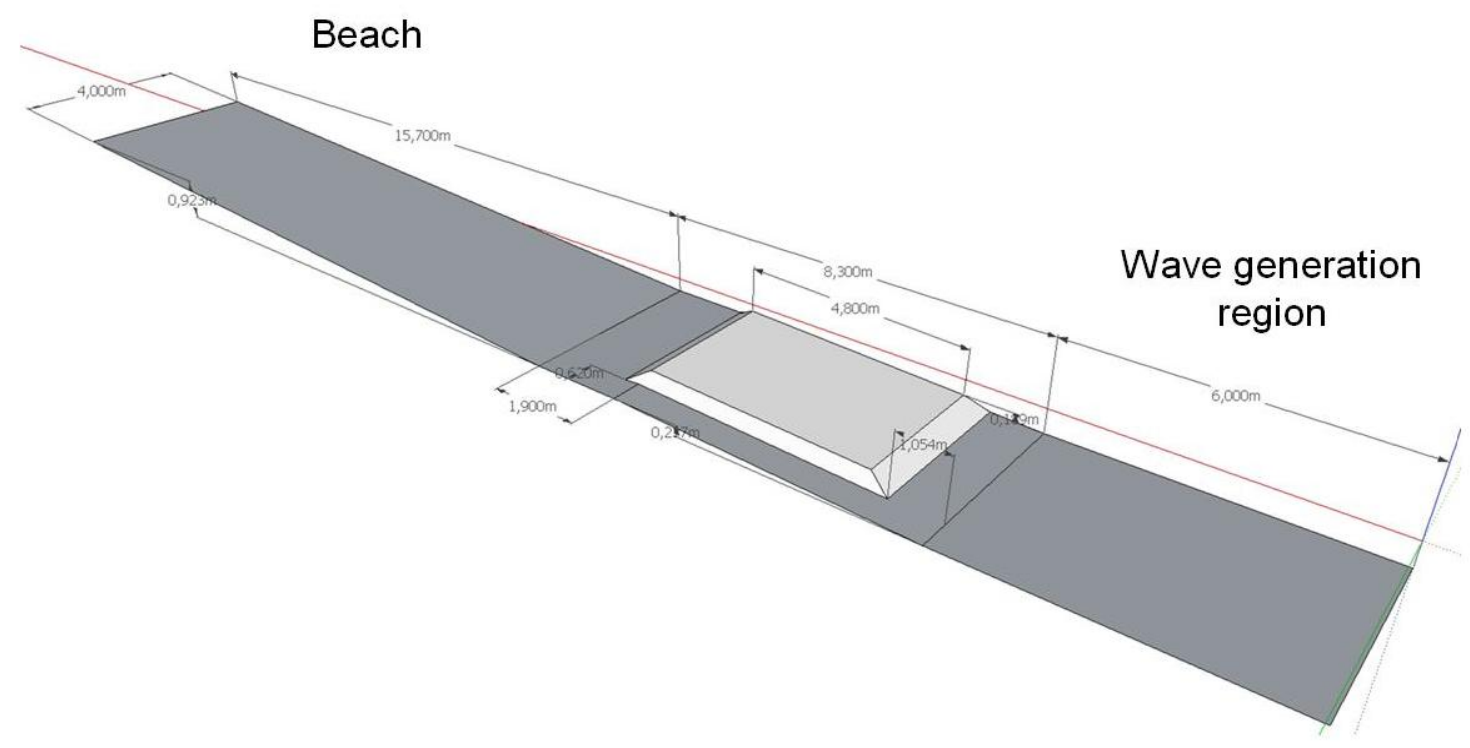

Figure 1. Sketch of the wave tank.

\section{Numerical Experiments}

The mesh reproduces the complete domain: $30 \mathrm{~m}$ long, $4 \mathrm{~m}$ wide and $1.2 \mathrm{~m}$ high. The initial discretization is $10 \mathrm{~cm}$ in the horizontal directions and $4.8 \mathrm{~cm}$ in the vertical one. After the mesh is intersected by the bathymetry ("snappyHexMesh") the cut cells are refined only once, since no run-up study is intended. The resolution in the bottom is then equal to $5 \mathrm{~cm}$ in the horizontal directions and 2.4 $\mathrm{cm}$ in the other one. The cells from $15 \mathrm{~cm}$ below and above the still water level are refined twice, ending up in $2.5 \mathrm{~cm}$ of horizontal resolution and $1.2 \mathrm{~cm}$ in the vertical one. This distance is chosen to refine even the trough of the bar, and to account for shoaling effects, the expected increase in wave height experimented by the wave-current interaction and the increase in the mean level due to the nearshore set-up. It also gets to refine the efficient swash zone of the final beach.

Since velocity measurements near the lateral walls are to be recorded and the resolution near them is not sufficient to represent the boundary layer, the walls and the bottom have been modelled using a free slip boundary condition. The final mesh totals 3.1 million cells. A total of 90 seconds were simulated, which corresponds to 60 wave periods. Using 24 cores $(2.6 \mathrm{GHz})$ almost 20 seconds were obtained per day.

The simulated case presents a regular wave train with $\mathrm{H}=15 \mathrm{~cm}$ and $\mathrm{T}=1.5 \mathrm{~s}$, with $5 \mathrm{~cm}$ of still water depth at the highest point of the bar. This allows waves to be discretized by more than 12 cells in height, so they are well defined. Waves are generated using Stokes II wave theory with active wave absorption connected. This is one of the advances without which this simulation could not be so accurate. It makes the whole boundary to behave as a unique wavemaker, generating the target waves, ensuring at the same time that reflected energy flows out and that the free surface level does not rise. Wave breaking starts in this simulation once the waves reach the bar, so it is a major driver factor. Another very important dynamic to account for is inundation of the swash zone, which influences the nearshore circulation patterns. This makes the boundary region a very important part of the simulation. Therefore, turbulence was decided to be modelled using the k- $\omega$ SST closure model.

\section{Validation}

Figure 2 presents the free surface (top panel) and the cross-shore velocity (bottom panel) evolution of a point within the rip channel. This point is located at the middle of the rip, in both horizontal directions $(x=10 \mathrm{~m}, \mathrm{y}=3.5 \mathrm{~m}$ in figure 1). Until $\mathrm{t}=25 \mathrm{~s}$, the water level rises as the wave set-up develops. From that point, the waves start to change due to the interaction with the opposing undertow current, which at that moment reaches its maximum value. The immediate result is that the waves increase in height. The stationary state is approximately reached at $\mathrm{t}=60 \mathrm{~s}$ of the simulation, with a decrease in current magnitude and wave height. After that moment, 30 more seconds are simulated in order to obtain the results as mean value over 20 waves. Such stationary state is achieved so early because of the linked wave generation and active wave absorption, otherwise the water level and the energetic level of the system would continue increasing. 

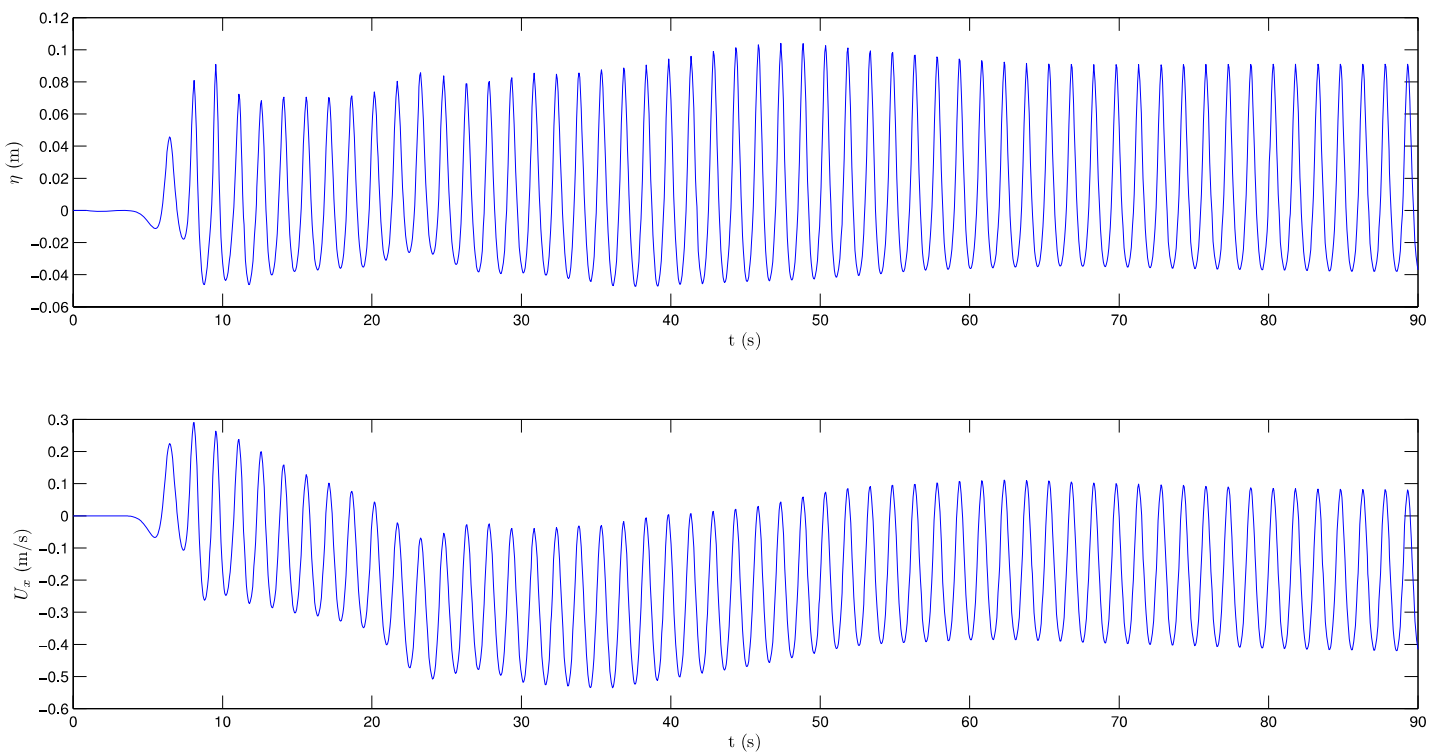

Figure 2: Evolution of the free surface (top panel) and cross-shore velocity (bottom panel) at 1/3 of the water depth from the bottom, within the rip channel $(X=10 \mathrm{~m}, Y=3.5 \mathrm{~m})$.

In Figure 3 the cross shore velocity in the rip channel as a function of long-shore positions at $\mathrm{x}=$ $11.40 \mathrm{~m}$ and $1 / 3$ depth from the bed are represented, comparing them with the experimental results in Dronen et al. (2002). The asterisks represent measured data, and the dashed line is the best fit proposed by Dronen. The continuous line represents the numerical data. OpenFOAM models correctly the velocity pattern within the cross section of the rip. The numerical shape is more or less linear, which contrasts with the apparent parabolic shape of the laboratory measurements. However, the results are very good as only differences of at most $5 \mathrm{~cm} / \mathrm{s}$ appear.

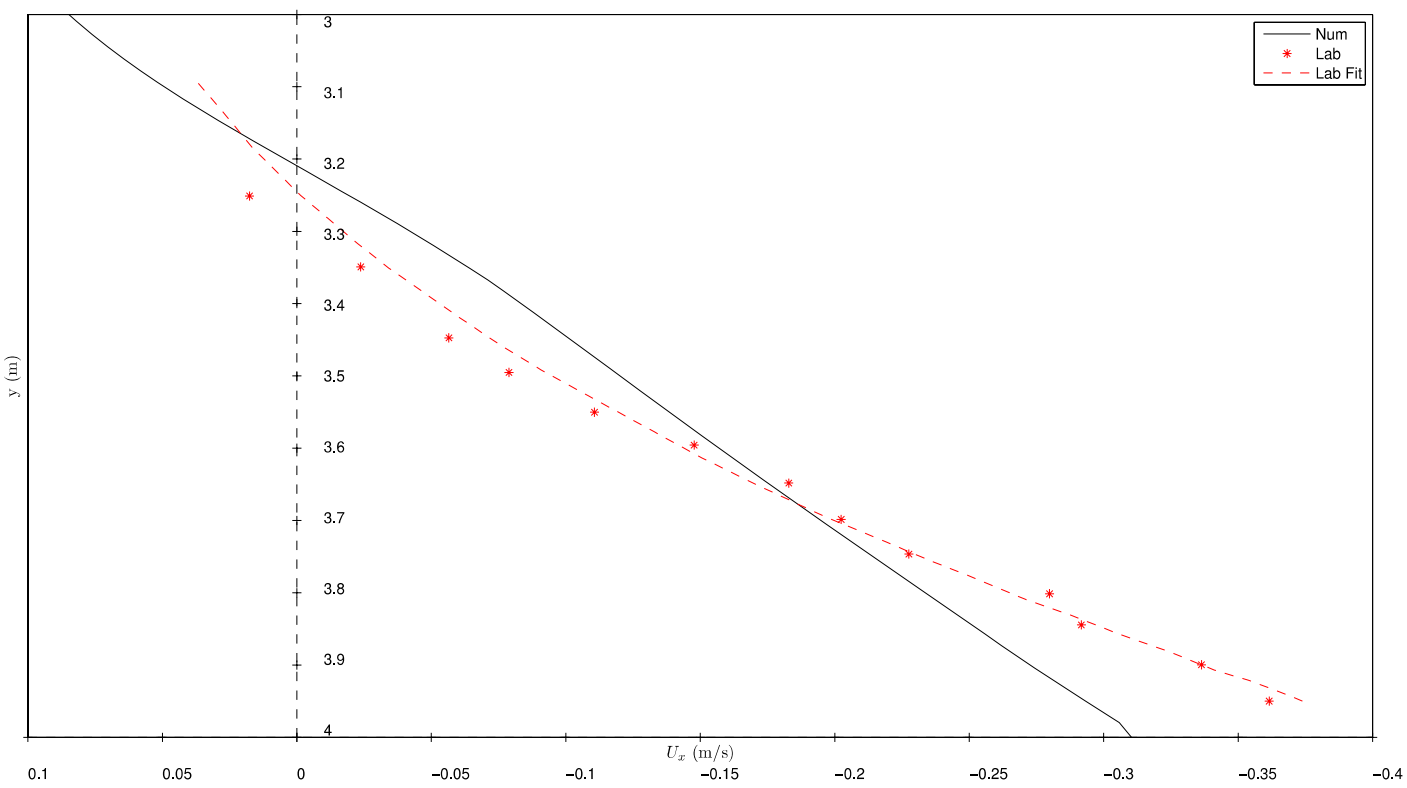

Figure 3: Cross-shore velocity as function of long-shore positions at $x=11.40 \mathrm{~m}$, at $1 / 3$ of the depth from the bed.

Figure 4 presents the depth-averaged velocity on a regular grid. Although the wave conditions for this case and the presented magnitudes are different, this figure can be compared with Figure 4 in Dronen et al. (2002). In this case the upgrade of the resolution helps to visualize the water circulation pattern. The most intense currents do not appear within the rip channel, but in its vicinity, where water is taken from. The main circulation pattern is formed, as expected, by the onshore current along the bar 
crest and the offshore current in the rip. There is also a secondary circulation which happens at the bar trough, where water flows from the rip to the bar in the section close to the shoreline and in the opposite direction near the bar crest. This double circulation has been described in the literature, including Haller et al. (2002), for topographically generated rip currents.

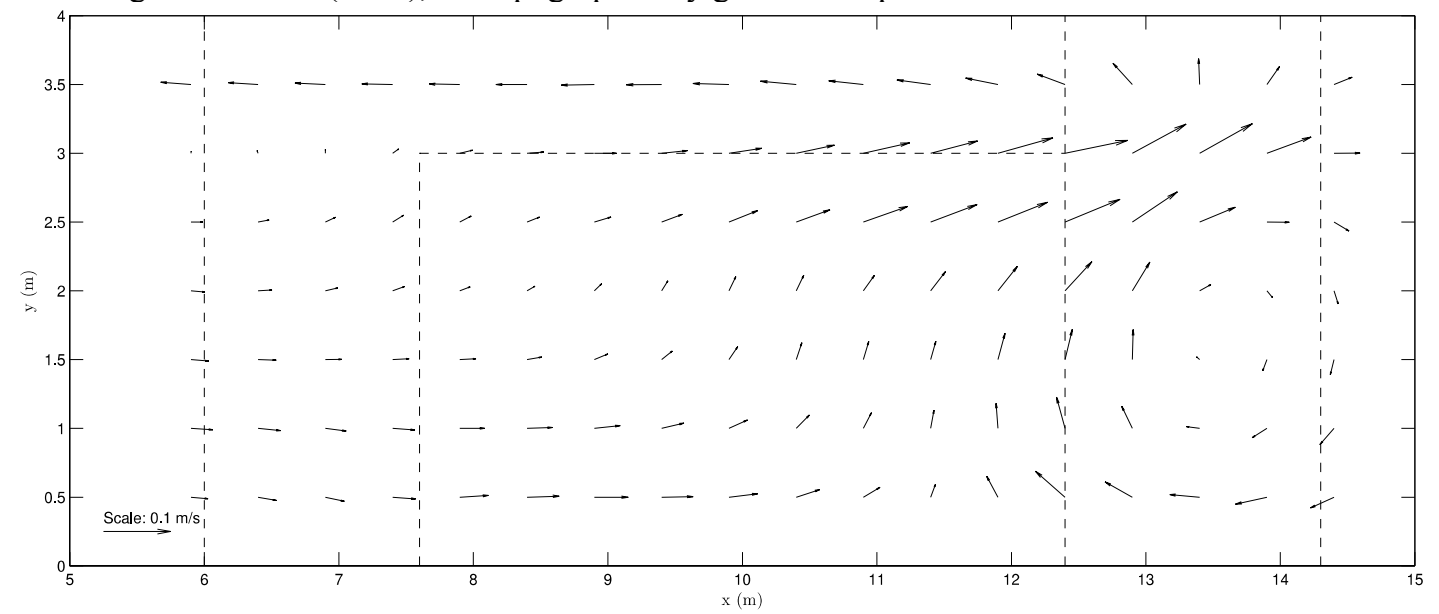

Figure 4: Depth-averaged currents. Waves come from the left.

As waves break over the bar, the residual energy is dissipated over a beach located at the end of the tank. A snapshot of a simulation of regular waves is represented in figure 5. Negative horizontal velocities observed in the cross-shore transect along the rip channel (lower panel) identify the development of a rip current.

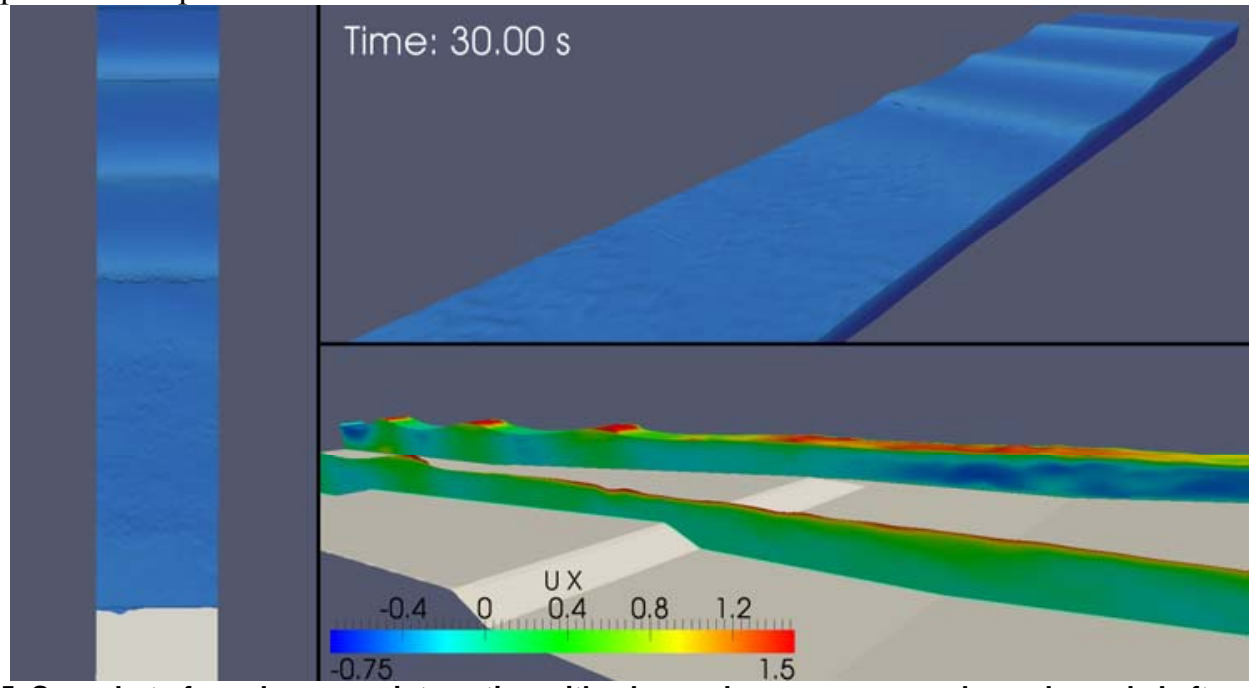

Figure 5. Snapshot of regular waves interacting with a bar and a narrow cross-shore channel. Left panel: top view of the free surface. Upper panel: side view of the free surface. Lower panel: cross shore transects of horizontal velocity.

\section{FURTHER RESULTS}

\section{Depth-averaged forcing}

The RANS-type numerical model IH-FOAM provides a means to obtain a high spatial and time resolution that is almost impossible to achieve in the laboratory. In particular, the high spatial resolution of numerical results enables a detailed study of the cross- and long-shore structure of the depth-averaged forcing of rip currents such as the mean set-up and the radiation stress. 


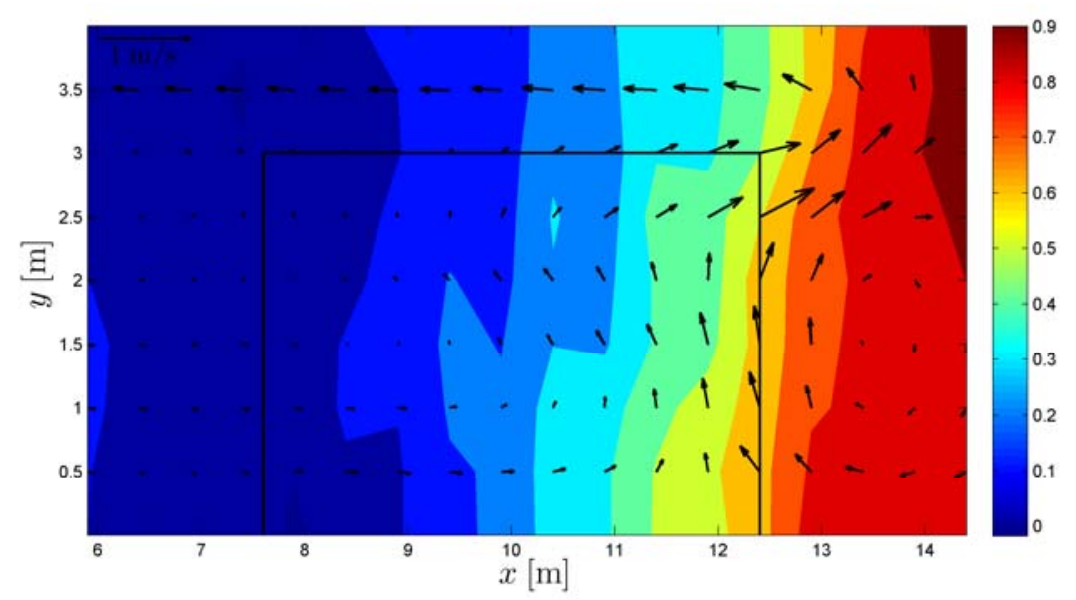

Figure 6. Mean surface elevation (set-up) in $\mathrm{cm}$. Black arrows indicate depth-averaged mean currents. Waves are propagating from left to right.

The mean surface elevation in the tank is plotted in figure 6. Moreover, black arrows show the depth-averaged mean circulation pattern. Close to the bar crest, the set-up over the bar is larger than the set-up over the rip channel, consistent with the intense breaking induced by the bathymetry. The resulting long-shore set-up gradient constitutes the forcing which drives the current flowing from the bar directly toward the rip channel. On the other hand, close to the shore, a long-shore set-up gradient positive toward the rip channel is observed. In fact, the strong dissipation in the channel related to wave breaking in very shallow waters enables a long-shore set-up gradient which drives the secondary circulation already observed in figure 4. The radiation stress field (not shown) mainly reflects the breaking pattern induced by the bar with a strong damping over the bar and close to the shoreline.

Investigations focused on rip current dynamics have shown that the dominant terms in the crossshore momentum balance are the radiation stress and set-up (Svendesen and Buhr Hansen 1986; Haller et al. 2002). Here, the set-up is compared with the mean water level predicted by the cross-shore depthaveraged momentum conservation equation:

$$
\overline{\zeta_{i+1}}=\overline{\zeta_{i}}-\frac{1}{\rho g h}\left(S_{x x_{i+1}}-S_{x x_{i}}\right)
$$

in which $\bar{\zeta}_{i}$ is the mean water level and $S_{x x_{i}}$ represents the radiation stress. In this case, the radiation stress is obtained directly from the free surface and velocity field provided by the numerical model. Figure 7 shows that the cross-shore variation of the set-up is mainly driven by the radiation stress gradient. In the bar-trough, the set-up predicted from the radiation stress gradient overestimates the observed set-up while the opposite happens in the rip channel. These observed differences are likely to be due to wave-current interactions not considered in equation (7). 

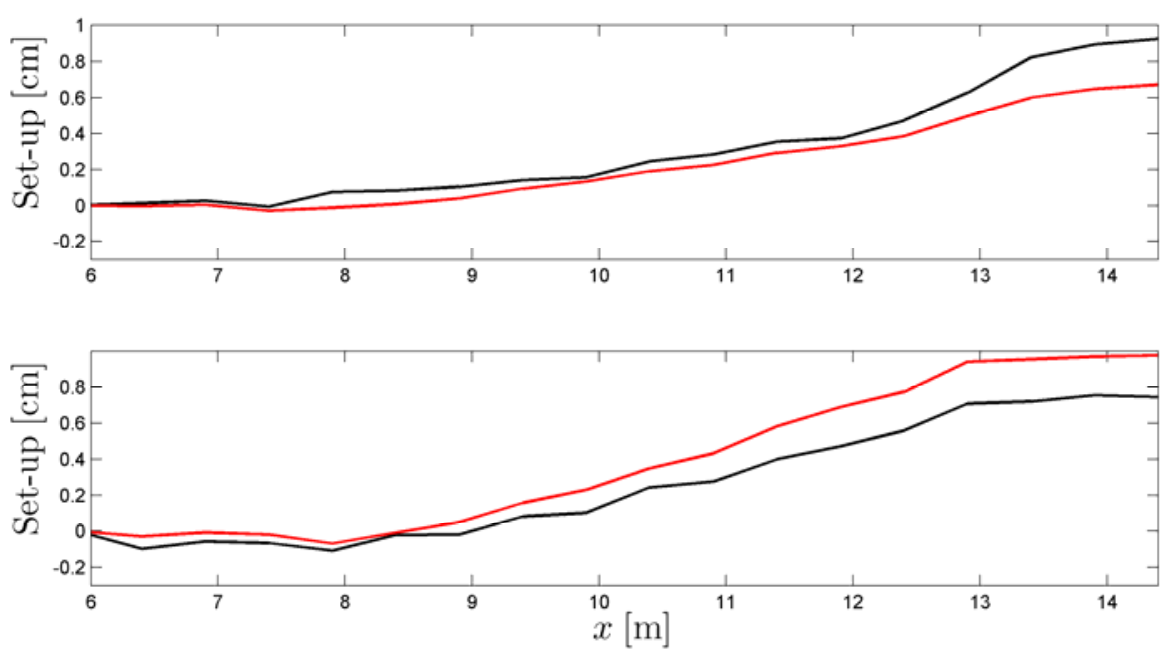

Figure 7. Cross-shore evolution of mean water level. Upper panel: rip channel; lower panel: rip-trough. Black line: observed; red line: calculated from radiation stress gradient (equation 7).

\section{Vertical structure of mean currents}

The model allows covering the entire water column including the zone above the wave trough where mean velocities are driven by the roller. The offshore directed flow in the rip channel is relatively uniform in the water column being slightly stronger near the bottom. Mean cross-shore horizontal velocities are positive along the column in the offshore part of the bar (left panel of figure 8). Above the bar crest, velocities take negative values near the bottom suggesting that undertow may play a significant role (right panel of figure 8).
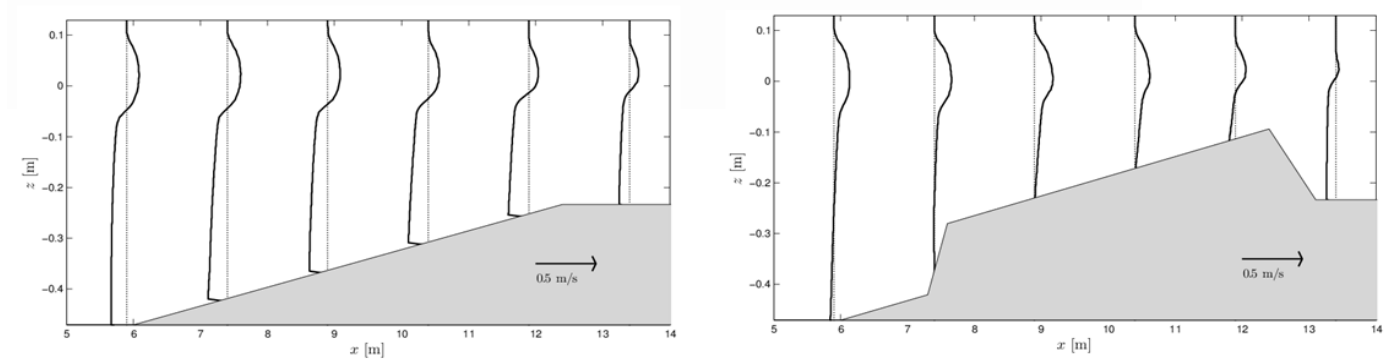

Figure 8. Cross-shore transect of mean currents. Left panel: rip channel; right panel: rip-trough.

The 3-dimensional structure of the currents is displayed in figure 9. In the rip channel the currents develop mainly in the cross-shore direction. The shoreward mass transport between the trough and crest levels is mainly induced by the roller, whereas strong seaward directed mean fluxes are present in the lower part of the column. Above the bar crest the shoreward fluxes induced by breaking waves are dominant in the upper part of the column. Below the trough level, mean current directions show a strong dependence on water depth. In fact, mean currents evolve along the water depth with near bottom velocities mainly long-shore directed. 


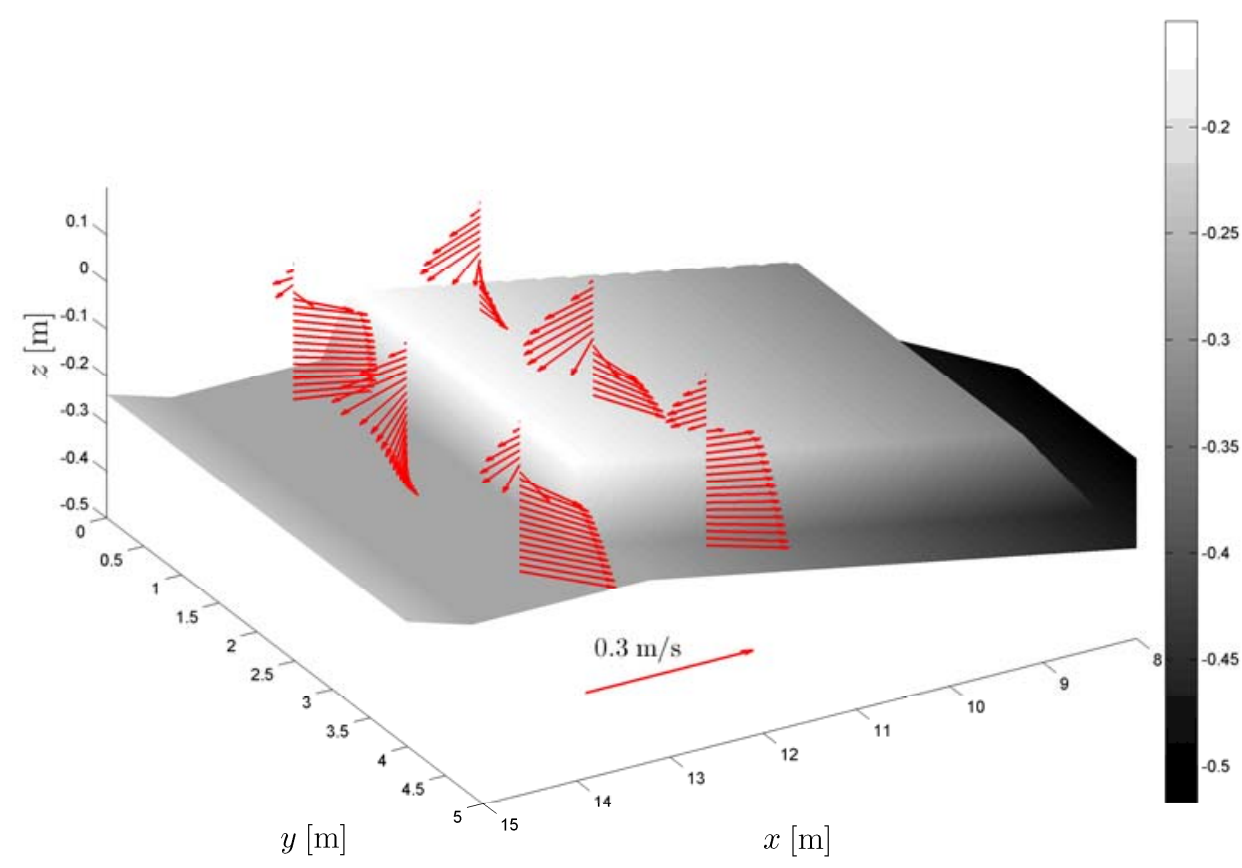

Figure 9. 3-dimensional structure of currents.

\section{CONCLUSIONS}

Wave generation and wave absorption implemented in the IH-FOAM model allow accurate coastal applications and the correct treatment of long simulations. The laboratory experiments of Dronen et al. (2002) are successfully reproduced by the numerical model. The velocity pattern observed within the rip channel and above the bar is correctly addressed. The secondary circulation with longshore flow from the rip channel toward the trough observed near the shore in the laboratory is reproduced as well.

The refined information provided by the model allows the detailed investigation of rip circulation on a barred beach such as the identification of the forcing mechanisms (mainly the radiation stress and set-up) and the 3D structure of the flow. Numerical results highlight the importance of the mean surface elevation gradients in the generation of longshore mean currents above the bar crest and in the bar trough. In addition, variations along the water depth have been reported: mean currents tend to be depth uniform and cross-shore oriented in the rip channel whereas they show a considerable three dimensional pattern above the bar crest with a marked long-shore component near the bottom.

\section{REFERENCES}

Dalrymple R.A., J.H. Macmahan, A.J. Reniers and V. Nelko. 2011. Rip currents. Annual Review of Fluid Mechanics.

Dronen, N., H. Karunarathna, J. Fredsoe, B. Sumer and R. Deigaard. 2002. An experimental study of rip channel flow. Coastal Engineering, 45:223-238.

Higuera, P., Lara, J.L., Losada, I.J. (2013a In Press). Realistic wave generation and active wave absorption for Navier-Stokes models. Application to OpenFOAM. Coastal Engineering. http://dx.doi.org/10.1016/j.coastaleng.2012.07.002

Higuera, P., Lara, J.L., Losada, I.J. (2013b In Press) Simulating Coastal Engineering Processes with OpenFOAM. Coastal Engineering. http://dx.doi.org/10.1016/j.coastaleng.2012.06.002

del Jesus, M., J.L. Lara and I.J. Losada. 2012. Three-dimensional interaction of waves and porous coastal structures. Part I: Numerical model formulation. Coastal Engineering. 64, 57-72.

Jacobsen, N.G., D.R. Fuhrman and J. Fredsøe. In Pess A wave generation toolbox for the open-source CFD library: OpenFoam. International Journal for Numerical Methods in Fluids.

Jasak, H. 1996. Error analysis and estimation for the finite volume method with applications to fluid flows. $\mathrm{PhD}$ thesis, Imperial College of Science, Technology and Medicine. 
Mendez, F.J., I.J. Losada and M.A. Losada. 2001. Wave-induced mean magnitudes in permeable submerged breakwaters. Journal of Waterway, Port, Coastal and Ocean Engineering, vol. 127, 715 .

Kissling, K., J. Springer, H. Jasak, S. Schütz, K. Urban and M. Piesche. 2010. A coupled pressure based solution algorithm based on the volume-of-fluid approach for two or more immiscible fluids. $V$ European Conference on Computational Fluid Dynamics, ECCOMAS CFD.

Lara, J.L., A. Ruju and I.J. Losada. 2011. Reynolds Averaged Navier-Stokes modelling of long waves induced by a transient wave group on a beach. Proceedings of the Royal Society A, vol. 467, 1215 1242.

Rusche, H. 2002. Computational fluid dynamics of dispersed two-phase flows at high phase fractions. Ph.D. thesis, Department of Mechanical Engineering, Imperial College of Science, Technology \& Medicine, London.

Schäffer, H.A. and G. Klopman. 2000. Review of multidirectional active wave absorption methods. Journal of Waterway, Port, Coastal and Ocean Engineering, March/April, 88-97.

Svendsen I.A. and J. Buhr Hansen. 1986. The interaction of waves and currents over a longshore bar. Coastal Engineering 1986: Proceedings of the $20^{\text {th }}$ International Conference, pp. 1580-1594, Am. Soc. of Civ. Eng., New York.

Torres-Freyermuth, A., J.L. Lara and I.J. Losada. 2010. Numerical modelling of short and long-wave transformation on a barred beach. Coastal Engineering, vol. 57, 317-330.

Wei, G. and J.T. Kirby. 1995. Time-dependent numerical code for extended Boussinesq equations. Journal of Waterway, Port, Coastal and Ocean Engineering, vol. 121 (5), 251-261. 